\title{
Influence of Family Involvement and Children's Socioemotional Development on the Learning Outcomes of Chilean Students
}

\author{
Mahia Saracostti ${ }^{*}$, Laura Lara ${ }^{2}$, Diana Martella ${ }^{3}$, Horacio Miranda ${ }^{4}$, \\ Edgardo Daniel Miranda-Zapata ${ }^{5}$ and Tal Reininger ${ }^{6}$
}

'Centro de Investigación sobre Procesos Socioeducativos, Familias y Comunidades, Núcleo Científico Tecnológico en Ciencias Sociales y Humanidades, Universidad de la Frontera, Temuco, Chile, ${ }^{2}$ Carrera de Psicología, Facultad de Ciencias Sociales y Humanidades, Universidad Autónoma de Chile, Talca, Chile, ${ }^{3}$ Carrera de Psicología, Facultad de Ciencias Sociales y Humanidades, Universidad Autónoma de Chile, Santiago, Chile, ${ }^{4}$ Núcleo Científico Tecnológico en Ciencias Sociales y Humanidades, Universidad de la Frontera, Temuco, Chile, ${ }^{5}$ Núcleo Científico Tecnológico en Ciencias Sociales y Humanidades, Universidad de la Frontera, Temuco, Chile, ${ }^{6}$ Escuela Escuela de Ciencias Sociales, Facultad de Educación y Ciencias Sociales, Universidad Andres Bello, Santiago, Chile

OPEN ACCESS

Edited by: Camilo Hurtado-Parrado, Troy University, United States

Reviewed by:

Joaquin Parra Martínez, University of Murcia, Spain Salvador Chacón-Moscoso, Universidad de Sevilla, Spain

*Correspondence: Mahia Saracosti mahia.saracostti@ufrontera.c

Specialty section: This article was submitted to Educational Psychology, a section of the journal Frontiers in Psychology

Received: 22 September 2018 Accepted: 04 February 2019 Published: 28 February 2019

Citation: Saracostti M, Lara L, Martella $D$, Miranda H, Miranda-Zapata E and Reininger T (2019) Influence of Family Involvement and Children's Socioemotional Development on the Learning Outcomes of Chilean Students. Front. Psychol. 10:335. doi: 10.3389/fpsyg.2019.00335
There is an extensive body of evidence to support both family involvement and students' socioemotional development as key factors in the promotion of learning outcomes. However, there is insufficient evidence to establish exactly what this impact is when both factors are considered simultaneously. Therefore, the aim of this study is to analyze the influence of family involvement and socioemotional development on learning outcomes of Chilean students, identifying the structure that most correctly identifies the influence of the predictor variables (family involvement and socioemotional development) on learning outcomes. We present the following three hypotheses that consider possible basic interrelation structures: (1) The influence of family involvement on learning outcomes is mediated by students' socioemotional development (mediation hypothesis); (2) The influence of family involvement on learning outcomes is moderated by students' socioemotional development (moderation hypothesis); (3) Family involvement and students' socio emotional development directly affect learning outcomes (covariance hypothesis). The structures were evaluated by means of a structural equation model analysis. The study included 768 students who attended second and third elementary grades in Chilean schools. The children were between 7 and 11 years old $(M=8.29, S D=0.86) ; 41.3 \%$ were girls and $58.7 \%$ were boys. The results show that family involvement and students' emotional development directly affect learning outcomes $(\mathrm{CFI}=0.995, \mathrm{TLI}=0.993$, RMSEA $=0.016)$. From the results, we can conclude that the data support the hypothesis that both family involvement and socioemotional development are predictors of learning outcomes, thereby rejecting that the impact of family involvement on learning outcomes is mediated or moderated by socioemotional development.

Keywords: family involvement, children's socioemotional development, learning, family and school relation, child development 


\section{INTRODUCTION}

The concept of family involvement has consistently emphasized the importance of and need for family support in children's education (Baker et al., 2016), which allows for a broader conceptualization of the roles of families and schools, their relations and the impact on children's development (Christenson and Sheridan, 2001; Patrikakou et al., 2005; Christenson and Reschly, 2010; Yamauchi et al., 2017). Family involvement is understood as the family's willingness to become involved with the school and their children's learning, including behavioral and verbal practices in the home and school activities (Anderson-Butcher, 2006).

Several studies indicate that family involvement has a positive influence on children's socioemotional development. (Gutman and Midgley, 2000; Fan and Chen, 2001; Garbacz et al., 2017). Several studies also indicate that family involvement has a positive influence on the development of children's abilities (Epstein and Sander, 2000; Vélez, 2009; Chavkin, 2017) and particularly on school learning outcomes (Brody et al., 1999; McWayne et al., 2004). Most of the studies in this area come from Anglo-Saxon (Garbacz et al., 2017) while in the Latin American context research is still scarce.

In his meta-analysis of 51 studies into family involvement programs, Jeynes (2012) concluded that reading programs shared between parents and children, programs focused on effective alliances, and programs focused on improving the communication between home and school had the greatest impact on children's academic performance. Another metaanalysis, after analyzing 46 studies identified that the key aspects explaining the positive correlation between learning outcomes and parental participation were the school-home connection (Ma et al., 2016). Finally, in a meta-analysis of 37 studies, Castro et al. (2015) found that the type of family participation that most affected students' academic performance was the parents having high expectations of their children, developing and maintaining a fluid communication about what happened at school, and promoting the development of reading habits.

In addition to the literature on the positive impact of family involvement on children's socioemotional development and learning outcomes, there is ample evidence of the relation between children's socioemotional development and learning outcomes (Jiménez and López-Zafra, 2009). It has generally been observed that positive emotions (e.g., pleasure in learning) are positively related to academic success, whereas negative emotions (e.g., anxiety) have an inverse relation (Goetz and Hall, 2013; Pekrun and Linnenbrink-Garcia, 2014). There are also studies that have found a statistically significant relationship between Emotion Quotient Inventory EQi- scores and academic performance (Bar-On, 1997; Parker et al., 2004) crucial for the education-learning process (Humphrey et al., 2007; Pekrun et al., 2017), nevertheless the results of some studies that have analyzed the relation between academic success and socio-emotional competence present ambiguous results (Newsome et al., 2000).

Due to the findings reviewed previously, we may conclude that there is evidence to support both family involvement and students' socioemotional development as key factors in the promotion of learning outcomes. We may also conclude that there is insufficient evidence to establish exactly what this impact is when both factors are considered simultaneously. Therefore, the aim of this study was to analyze the influence of family involvement and socioemotional development on learning outcomes of Chilean students, identifying the structure that most correctly identifies the influence of the predictor variables (family involvement and socioemotional development) on learning outcomes. The following three hypotheses were considered possible basic interrelation structures (Figure 1):

(A) The influence of family involvement on learning outcomes is mediated by students' socioemotional development (mediation hypothesis);

(B) The influence of family involvement on learning outcomes is moderated by students' socioemotional development (moderation hypothesis);

(C) Family involvement and students' socio emotional development directly affect learning outcomes (covariance hypothesis)

\section{MATERIALS AND METHODS}

\section{Participants}

The study included 768 students who attended second and third elementary grades in 18 schools in regions in Chile (O'Higgins, El Maule and La Araucanía). The children were between 7 and 11 years old $(M=8.29, S D=0.86) ; 41.3$ and $58.7 \%$ were girls and boys, respectively.
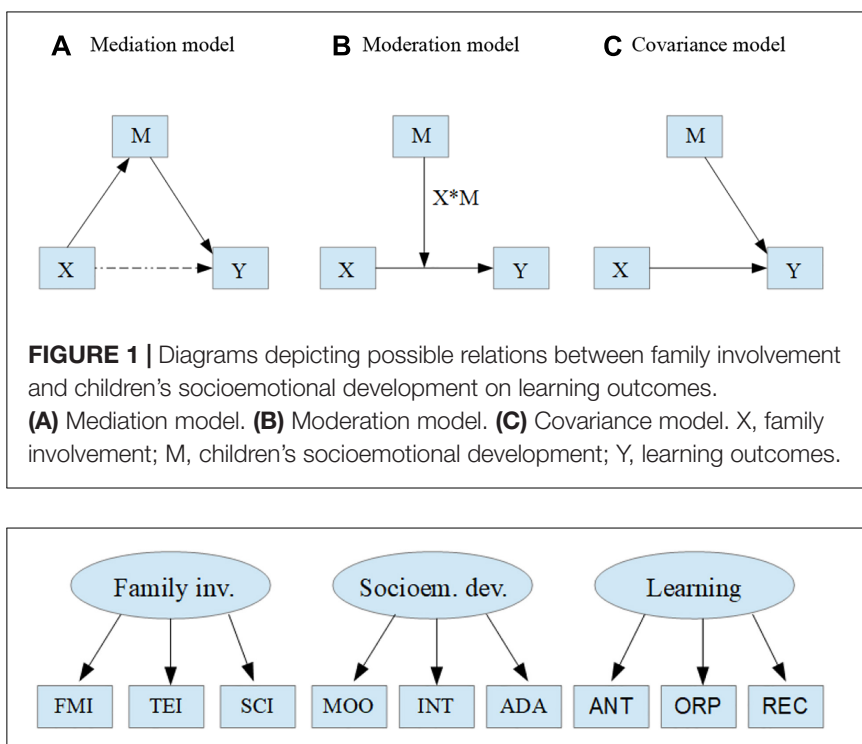

FIGURE 2 | Constructs and subdimensions. Family inv., components of family involvement; FMI, father/mother involvement; TEl, teacher involvement; SCI, school involvement; Socioem. dev., components of socio-emotional development; MOO, mood; INT, interpersonal; ADA, adaptability; Learning, components of learning; ANT, analogical thinking; ORP, organizational perspectives; REC, reading comprehension. 


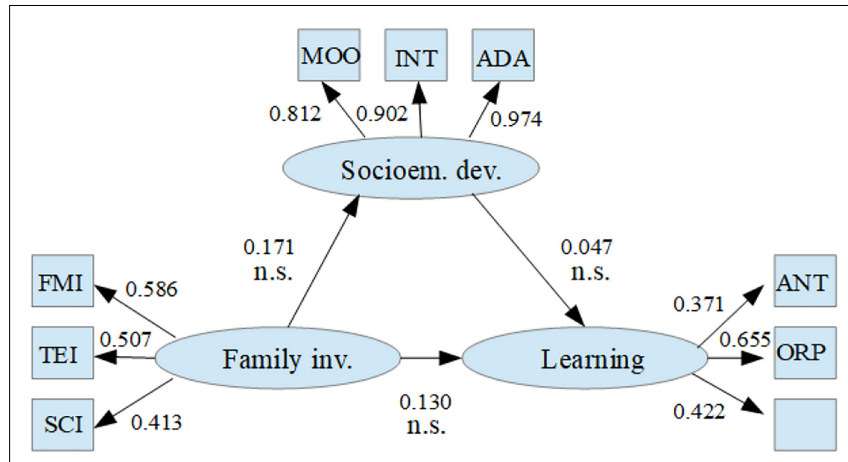

FIGURE 3 | Path diagram of the theoretical mediation model. Family inv., components of family involvement; FMI, father/mother involvement; TEI, teacher involvement; SCI, school involvement; Socioem. dev., components of socio-emotional development; MOO, mood; INT, interpersonal; ADA, adaptability; Learning, components of learning; ANT, analogical thinking; ORP, organization perspectives; REC, reading comprehension; n.s.,

non-significative difference.

Participants were selected using non-probability purposive sampling (Kerlinger and Lee, 2002), as is the case of the students included in this study, who come from schools that offer elementary education and have been described as having high levels of vulnerability according to the student vulnerability index issued by the Chilean Ministry of Education.

This study was carried out in accordance with the recommendations of the Chilean National Commission for Scientific and Technological Research. The protocol was approved by the Ethics Committee of the Universidad de La Frontera (Acta 066-2017, Folio 036-17). All the subjects provided written informed consent in accordance with the Declaration of Helsinki

\section{Instruments}

\section{Assessment of Family Involvement}

Three scales of the Hoover-Dempsey and Sandler (2005) Parental Involvement Scale translated into Spanish and validated by a panel of experts in Chile (Reininger, 2014) were used in this study: The Parental Involvement forms (with two subscales: home based involvement, 5 items, and school based involvement, 5 items); the teacher invitations for involvement scale (6 items); and the general school invitations scale (6 items). The fist scale has a four-point Likert response scale, from 1 (never) to 4 (always), while the rest was a 5-point scale Likert response, from 1 (strongly disagree) to 5 (strongly agree).

\section{Evaluation of Learning Outcomes}

Three subtest of the educational psychology battery EVALÚA (García and González, 1999; García et al., 2006) were used in this study: Reading Comprehension (22 items) and two subtest of reasoning, Analogical Thinking (20 items) and Perceptual Organization (34 items).

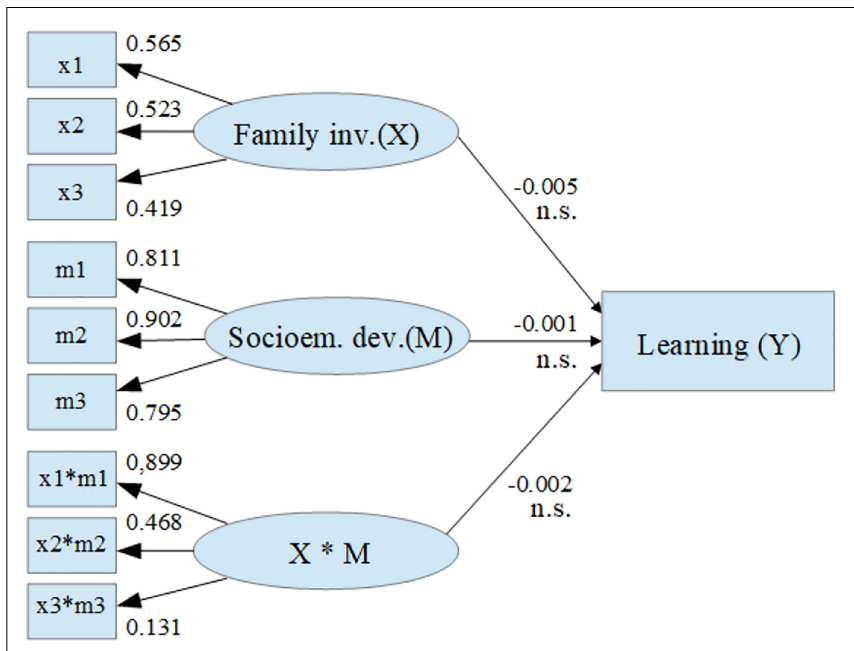

FIGURE 4 | Path diagram of the moderation model. Family inv.(X), components of family involvement; $x 1$, father/mother involvement; $x 2$, teacher involvement; $x 3$, school involvement; Socioem. dev.(M), components of socioemotional development; m1, mood; m2, interpersonal; m3, adaptability; Learning $(Y)$, learning; $X^{*} M$, multiply of indicators variables; $x 1 m 1$,

father/mother involvement by mood multiply; $x 2 \mathrm{~m} 2$, teacher involvement by interpersonal multiply; $\times 3 \mathrm{~m} 3$, school involvement by adaptability multiply; n.s., non-significative difference at $5 \%$.

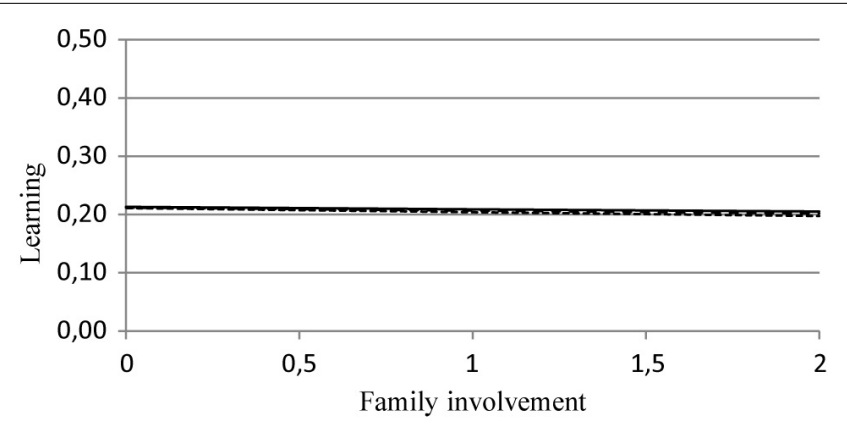

Socioem.dev.(-1) - - - Socioem.dev.(0) ------- Socioem.dev.(1)

FIGURE 5 | Graph of regression lines for the moderation model. Socioem. dev., socioemotional development.

\section{Assessment of Socioemotional Development}

Three dimensions of the EQ-I: YV questionnaire (Bar-On and Parker, 2000) adapted and validated in Spanish (Ferrándiz et al., 2012) were used in this study: interpersonal (12 items), adaptability (10 items) and general mood (14 items). The response scale ranged from 1 (rarely) to 4 (nearly always).

The coefficient omega average of MacDonald to ordinal scales was 0.96 to Socio-Emotional (0.78-0.97), 0.88 to Family involvement (0.78-0.84) and alpha 0.81 to Learning.

\section{Procedure}

This study is part of a wider project focusing on the effectiveness of interventions to strengthen the link between families and schools. 
TABLE 1 | Estimations of the structural parameters of the mediation model.

\begin{tabular}{|c|c|c|c|c|c|c|c|}
\hline & & Effect of. & Est.no std. & S.E. & Est./S.E. & Sig. Est.Std. & Sig. \\
\hline Learning & <- Family inv. & 0.130 & 0.085 & 1.523 & 0.128 & 0.132 & n.s. \\
\hline Learning & <- Socioem. dev. & 0.047 & 0.038 & 1.225 & 0.221 & 0.092 & n.s. \\
\hline Socioem. dev. & <- Family inv. & 0.171 & 0.113 & 1.513 & 0.130 & 0.088 & n.s. \\
\hline
\end{tabular}

Family inv., family involvement; Socioem. dev., socioemotional development; Learning, learning; n.s., non-significative difference at 5\%.

TABLE 2 | Confidence intervals for the estimations of the structural parameters of the mediation model.

\begin{tabular}{|c|c|c|c|c|c|c|c|c|}
\hline Confidence interval & & inf.99\% & inf. $95 \%$ & inf. $90 \%$ & Estim. & sup. $90 \%$ & sup. $95 \%$ & sup. $99 \%$ \\
\hline Learning & <- Family inv. & -0.023 & -0.011 & 0.027 & 0.130 & 0.319 & 0.366 & 0.460 \\
\hline Learning & <-Socioem. dev. & -0.020 & -0.008 & -0.002 & 0.047 & 0.124 & 0.141 & 0.179 \\
\hline Socioem. dev. & $<-$ Family inv. & -0.125 & -0.034 & 0.004 & 0.171 & 0.373 & 0.413 & 0.497 \\
\hline Ef.ind.specific & & -0.013 & -0.008 & -0.005 & 0.008 & 0.021 & 0.024 & 0.029 \\
\hline
\end{tabular}

Family inv., family involvement; Socioem. dev., socioemotional development; Learning, learning; Ef.ind.specific, specific indirect effect.

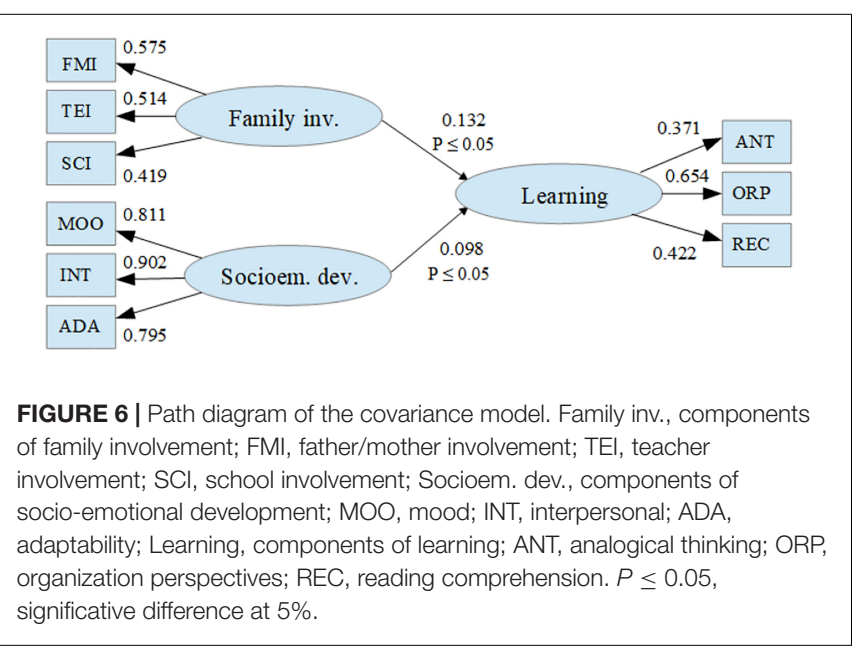

The data referring to the students (evaluation of learning outcomes and assessment of socioemotional development) was collected during school hours and were registered in digital format in the schools' computer rooms during three sessions. The data referring to the families (family involvement) were collected in paper format during parent teacher meetings.

\section{Analysis Plan}

In the first phase of data processing, inverse items were recoded, response rates were verified and corrected, unanswered records were identified and eliminated and non-parametric

TABLE 3 | Regression slopes for the moderation model.

\begin{tabular}{lccccc}
\hline Socioem. dev. & Mod & Slope & SE & Wald & Sig. \\
\hline Low & -1 & -0.0024 & 0.021 & -0.12 & 0.91 \\
Medium & 0 & -0.0049 & 0.014 & -0.36 & 0.72 \\
High & 1 & -0.0074 & 0.021 & -0.36 & 0.72
\end{tabular}

Socioem. dev., socioemotional development; Mod, moderator variable level (socioemotional development). multiple imputation of classification and regression trees with random-forest resampling was used for missing data (Stekhoven and Bühlmann, 2012), which enables imputation for ordinal variables. In order to center the focus of the causal model on the predictive structure of the factors, the factorial scores of the subdimensions for the family involvement scale and those of socioemotional development and school learning were calculated (Figure 2), these consisting of the subscales with loads greater than 0.40 (Stevens, 2009; Brown, 2015).

Once the factorial scores of the selected subscales were calculated, these subsequently occupied the role of indicator variables for each construct. Using this configuration of components, several structural equation models were fit to determine the structure of the causal relationship between the two factors considered as antecedents (family involvement and socioemotional development) of school learning. The structures of the trajectories studied were a relation of mediation, moderation and covariance as shown in Figure 1.

In order to evaluate the fit of the models to the data, the following indices were used: comparative fit index (CFI), TuckerLewis index (TLI) and root mean square error of approximation (RMSEA); for the first indices, CFI and TLI, values above 0.90 or 0.95 are considered an adequate fit of the model (Schreiber et al., 2006), while for the RMSEA values below 0.08 are considered a reasonable fit (Hooper et al., 2008).

For the case of the mediation effect, statistical significance was used and the estimation of the confidence intervals by means of resampling of the specific indirect effect attributable to the presence of the mediator variable (Muthén and Asparouhov, 2015). In order to evaluate the moderation effect, a multiplicative model was used that included the product of the indicator variables of the two factors used as antecedents (Marsh et al., 2004). Finally, to evaluate the presence of a structure with covariance effect, an analysis was performed of the statistical significance of regression slopes applied to the trajectories of the latent variables of the model. The statistics software used was Mplus 7.11 as well as the miss Forest, laavan and sem Tools packages in $\mathrm{R}$. 


\section{RESULTS}

The mediation model (Figure 3) revealed low levels of indirect relation of family involvement mediated by socioemotional development to the response of school learning; these results allow the presence of an indirect and mediating effect to be ruled out, leaving open the possibility that the effect of family involvement on learning can take the form of a moderated relation or interaction, or assume a direct and independent role of socioemotional development.

The results of the model demonstrated high levels of goodness of fit, with CFI and TL values of 0.995 and 0.993 , respectively; in turn, a low error of estimation was observed with a RMSEA of 0.016, which confirms the stability of the results. On the other hand, the estimations of the parameters of the mediation model showed low and non-significant levels of the mediation effect, which leads to the conclusion that mediation is not the structure of relation between the study variables (Table $\mathbf{1}$ ).

This was also corroborated by the estimation of the confidence intervals for significance levels of 1 and 5\%, both for the sum of the mediation effect and for the estimation of its specific effect (Table 2).

Based on the results of the evaluation of the mediation effect, it is possible to conclude that there is no significant evidence in any of the parameters of the model $(p>0.05)$ to corroborate that the relation between the study variables is a model with mediation effect. Therefore, with the hypothesis of the mediation effect being discarded, it becomes necessary to evaluate the models corresponding to the effects of moderation and covariance.

In relation to the moderation hypothesis, the results showed that incorporating the interaction effect of the exogenous variables means that all the effects are statistically non-significant (Figure 4).

This is confirmed through an analysis of the slopes of each level of socioemotional development, which are not statistically different from zero (Table 3). The intercept analysis was dismissed, as the indicator variables were centered prior to the statistical analysis of the moderation model.

These findings were also corroborated by the presence of parallelism in the graph of the regression lines (Figure 5), resulting from the interaction between the independent variable of family involvement and the variable that acted as moderator in the model, which in this case was socioemotional development.

Based on the evidence verified in the evaluation of the interaction model, it is possible to conclude that the hypothesis regarding a moderation effect of socioemotional development on the relation of family involvement and school learning is rejected.

Finally, due to the rejection of the two previous hypotheses corresponding to the mediation and moderation models, in this section the results obtained in the verification of the statistical significance of a covariance model are described. The results showed that family involvement and students' emotional development directly affect learning outcomes $(\mathrm{CFI}=0.995$, TLI $=0.993$, RMSEA $=0.016)$, explaining $69 \%$ of the learning variance. This allows to conclude that in the context of the analyzed data, socioemotional development participates directly and independently in school learning in a similar way although to a lesser degree $\left(\gamma_{21}=0.098, p=0.049\right)$ than family involvement $\left(\gamma_{23}=0.132\right.$, $p=0.032)$ (Figure 6).

\section{DISCUSSION}

International literature indicates that the degree of family involvement in school processes is a critical element in the development and learning outcomes of children during their first school years (Hoover-Dempsey and Sandler, 1997; Caspe et al., 2006) making relevant the need to generate scientific evidence from the Chilean context for eventual future replications in other Latin American countries.

The results of the present study support the hypothesis that both family involvement and socioemotional development are predictors of learning outcomes, thereby rejecting the notion that the impact of family involvement on learning outcomes is mediated or moderated by socioemotional development. In this sense, both factors are positioned as dimensions with a direct effect on learning outcomes in the case of Chilean students.

One of the main contribution of this study is its focus on Latin America due to the lack of literature from this region. For example, in a recent systematic review, only one Mexican study from 1998 appeared, which was strongly influenced by U.S. interventions (Eichin and Volante, 2018). In this context, Chile has acknowledged the importance of collaborative relationships between families and schools leading to the development a National Policy for Father, Mother and Legal Guardian Participation. Nevertheless, the majority of research in the country has thus far been of a qualitative nature with a focus on describing family school relations and identifying tensions between these two spheres (Gubbins, 2011). Thus, this study aimed to make progress in the analysis of the effect of parental involvement in school and children's socioemotional development on learning outcomes of Chilean students.

One of the main weaknesses is that the study utilized a thematic or convenience sample. Therefore, one of the main challenges for future research in Chile and Latin America is the need for studies with probabilistic samples.

\section{AUTHOR CONTRIBUTIONS}

MS developed the study concept and the study design. LL and DM substantially contributed to the study concept and the study design. DM, TR, and LL performed the data collection. HM and EM-Z performed the data analysis and interpretation under the supervision of MS and LL. MS, LL, and DM drafted the 
manuscript. DM, TR, LL, HM, and EM-Z substantially contributed to the interpretation of the data and provided important critical revisions. All authors approved the final version of the manuscript and also agreed to be accountable for all aspects of the work.

\section{REFERENCES}

Anderson-Butcher, D. (2006). "Building effective family support programs and interventions," in The School Services Sourcebook: A Guide for School-Based Professionals, eds C. Franklin, M. B. Harris, and P. Allen-Meares (New York, NY: Oxford University Press), 651-661.

Baker, T. L., Wise, J., Kelley, G., and Skiba, R. J. (2016). Identifying barriers: creating solutions to improve family engagement. School Commun. J. 26, 161-184.

Bar-On, R. (1997). Emotional Intelligence in Men and Women, Bar On Emotional Quotient Inventory: Technical Manual. Toronto: Mult iHealth System.

Bar-On, R., and Parker, J. D. A. (2000). Emotional Quotient Inventory: Youth Version (EQ-i:YV). Technical Manual. Toronto: Multi-Health Systems.

Brody, G., Flor, D. L., and Gibson, N. M. (1999). Linking maternal efficacy beliefs, developmental goals, parenting practices, and child competence. Child Dev. 70, 1197-1208. doi: 10.1111/1467-8624.00087

Brown, T. A. (2015). Confirmatory Factor Analysis for Applied Research, 2nd Edn. New York, NY: The Guilford Press.

Caspe, M., Lopez, M. E., and Wolos, C. (2006). Family Involvement in Elementary School Children's Education. Family Involvement Makes a Difference: Evidence that Family Involvement Promotes School Success for Every Child of Every Age. Cambridge, MA: Harvard Family Review Project.

Castro, M., Expósito-Casas, E., López-Martín, E., Lizasoain, L., NavarroAsencio, E., and José Luis Gaviria, J. L. (2015). Parental involvement on student academic achievement: a meta-analysis. Educ. Res. Rev. 14, 33-46. doi: 10.1016/ j.edurev.2015.01.002

Chavkin, N. F. (2017). Family Engagement with Schools: Strategies for School Social Workers and Educators. New York, NY: Oxford University Press. doi: 10.1093/ acprof:oso/9780190642129.001.0001

Christenson, S. L., and Reschly, A. L. (eds) (2010). Handbook of School-Family Partnerships. New York, NY: Routledge. doi: 10.4324/9780203876046

Christenson, S. L., and Sheridan, S. M. (2001). School and Families: Creating Essential Connections for Learning. New York, NY: The Guildford Press.

Eichin, N., and Volante, P. (2018). Leading school, family and community partnerships: a critical review. Rev. Compl. Educ. 29, 595-611.

Epstein, J., and Sander, M. (2000). Handbook of the Sociologic of Education. New York, NY: Springer.

Fan, X., and Chen, M. (2001). Parental involvement and students' academic achievement: a meta-analysis. Educ. Psychol. Rev. 13, 1-22. doi: 10.1023/A: 1009048817385

Ferrándiz, C., Hernández, D., Bermejo, R., Ferrando, M., and Sáinz, M. (2012). Social and emotional intelligence in childhood and adolescence: spanish validation of a measurement instrument. Rev. Psicodidáct. 17, 309-338. doi: 10.1387/Rev.Psicodidact.2814

Garbacz, S. A., Herman, K. C., Thompson, A. M., and Reinke, W. M. (2017). Family engagement in education and intervention: implementation and evaluation to maximize family, school, and student outcomes. J. School Psychol. 62, 1-10. doi: 10.1016/j.jsp.2017.04.002

García, J., García, B., and González, D. (2006). Batería Psicopedagógica Evalúa-3: Manual de la Segunda Edición. Madrid: Editorial EOS.

García, J., and González, D. (1999). Batería Psicopedagógica Evalúa-2: Ámbito Óptimo de Utilización, $2^{\circ}$ Curso del[sic] Educación Básica. Madrid: Editorial EOS.

Goetz, T., and Hall, N. (2013). "Emotion and achievement in the classroom," in International Guide to Student Achievement, Educational Psychology Handbook Series, ed. J. Hattie (London: Routledge), 192-195.

Gubbins, V. (2011). Estrategias de Involucramiento Parental de Estudiante con Buen Rendimiento Escolar en Educación Básica. Doctoral Dissertation, Pontificia Universidad Catolica de Chile, Santiago.

Gutman, L. M., and Midgley, C. (2000). The role of protective factors in supporting the academic achievement of poor African American students

\section{FUNDING}

This work was supported by FONDECYT 1170078 of the National Commission for Scientific and Technological Research of Chile.

during the middle school transition. J. Youth Adolesc. 29:223. doi: 10.1023/A: 1005108700243

Hooper, D., Coughlan, J., and Mullen, M. (2008). Structural equation modelling: guidelines for determining model fit structural equation modelling: guidelines for determining model fit. Electron. J. Bus. Res. Methods 6, 53-60. doi: 10.1037/ 1082-989X.12.1.58

Hoover-Dempsey, K., and Sandler, H. (1997). Why do parents become involved in their children's education? Rev. Educ. Res. 67, 3-42. doi: 10.3102/ 00346543067001003

Hoover-Dempsey, K., and Sandler, H. (2005). The Social Context of Parental Involvement: A Path to Enhanced Achievement. Nashville, TN: Vanderbilt University.

Humphrey, N., Curran, A., Morris, E., Farrel, P., and Woods, K. (2007). Emotional intelligence and education: a critical review. Educ. Psychol. 27, 235-254. doi: 10.1080/01443410601066735

Jeynes, W. H. (2012). A meta-analysis of the efficacy of different types of parental involvement programs for urban students. Urban Educ. 47, 706-742. doi: 10. $1177 / 0042085912445643$

Jiménez, M. I., and López-Zafra, E. (2009). Inteligencia emocional y rendimiento escolar: estado actual de la cuestión. Rev. Latinoam. Psicol. 41, 69-79.

Kerlinger, F. N., and Lee, H. B. (2002). Investigación del Comportamiento: Métodos de Investigación en Ciencias Sociales. México: McGraw-Hill Interamericana.

Ma, X., Shen, J., Krenn, H. Y., Hu, S., and Yuan, J. (2016). A metaanalysis of the relationship between learning outcomes and parental involvement during early childhood education and early elementary education. Educ. Psychol. Rev. 28, 771-801. doi: 10.1007/s10648-0159351-1

Marsh, H. W., Wen, Z., and Hau, K.-T. (2004). Structural equation models of latent interactions: evaluation of alternative estimation strategies and indicator construction. Psychol. Methods 9, 275-300. doi: 10.1037/1082-989x.9.3.275

McWayne, C., Hampton, V., Fantuzzo, J., Cohen, H. L., and Sekino, Y. (2004). A multivariate examination of parent involvement and the social and academic competencies of urban kindergarten children]. Psychol. Schools 41, 363-377. doi: 10.1002/pits. 10163

Muthén, B., and Asparouhov, T. (2015). Causal effects in mediation modeling: an introduction with applications to latent variables. Struct. Equ. Model. 22, 12-23. doi: 10.1080/10705511.2014.935843

Newsome, S., Catano, A. L., and Day, V. M. (2000). Assessing the predictive validity of emotional intelligence. Pers. Individ. Diff. 29, 1005-1016. doi: 10.1016/S01918869(99)00250-0

Parker, J. D. A., Creque, R. E., Barnhart, D. L., Harris, J. I., Majeski, S. H., Wood, L. M., et al. (2004). Academic achievement in high school: does emotional intelligence matter? Pers. Individ. Diff. 37, 1321-1330. doi: 10.1016/j.paid.2004. 01.002

Patrikakou, E., Weisberg, R. P., Redding, S., and Walberg, H. J. (2005). "Schoolfamily partnerships: enhancing the academic, social, and emotional learning of children," in School-Family Partnerships for Children's Success, eds E. P. Patrikakou, R. P. Weisberg, S. Redding, and H. J. Walberg (New York, NY: Teachers College Press), 1-20.

Pekrun, R., Lichtenfeld, S., Marsh, H. W., Murayama, K., and Goetz, T. (2017). Achievement emotions and academic performance: longitudinal models of reciprocal effects. Child Dev. 88, 1653-1670. doi: 10.1111/cdev.12704

Pekrun, R., and Linnenbrink-Garcia, L. (2014). International Handbook of Emotions in Education. London: Routledge. doi: 10.4324/9780203148211

Reininger, T. (2014). Parental Involvement in Municipal Schools in Chile: Why do Parents Choose to Get Involved? Ph.D. Dissertation, Fordham University Graduate School of Social Service, New York, NY.

Schreiber, J., Nora, A., Stage, F., Barlow, E., and King, J. (2006). Reporting structural equation modeling and confirmatory factor analysis results: a review. J. Educ. Res. 99, 323-337. doi: 10.3200/JOER.99.6.323-338 
Stekhoven, D. J., and Bühlmann, P. (2012). MissForest-non-parametric missing value imputation for mixed-type data. Bioinformatics 28, 112-118. doi: 10.1093/ bioinformatics/btr597

Stevens, J. P. (2009). Applied Multivariate Statistics for Social Sciences, 5th Edn. New York, NY: Routledge.

Vélez, R. (2009). La relación familia-escuela como alianza. Aproximaciones a su comprensión e indagación. Rev. Educ. Innov. Tecnol. $3,1-15$.

Yamauchi, L. A., Ponte, E., Ratliffe, K. T., and Traynor, K. (2017). Theoretical and conceptual frameworks used in research on family-school partnerships. School Commun. 27, 9-34. doi: 10.1186/s12889-018-5412-y
Conflict of Interest Statement: The authors declare that the research was conducted in the absence of any commercial or financial relationships that could be construed as a potential conflict of interest.

Copyright (c) 2019 Saracostti, Lara, Martella, Miranda, Miranda-Zapata and Reininger. This is an open-access article distributed under the terms of the Creative Commons Attribution License (CC BY). The use, distribution or reproduction in other forums is permitted, provided the original author(s) and the copyright owner(s) are credited and that the original publication in this journal is cited, in accordance with accepted academic practice. No use, distribution or reproduction is permitted which does not comply with these terms. 